\title{
A HIGH-FIELD, HIGH-DENSITY TOKAMAK POWER REACTOR
}

\section{BY}

D. R. COHN, D. L, COOK, R, D. HAY,

D. KAPLAN, K. KREISCHER, L. M. LIDSKY,

W. STEPHANY, J,E, C. WILLIAMS, AND

D. L. JASSBY, M, OKABAYASHI

\section{PLASMA PHYSICS LABORATORY}
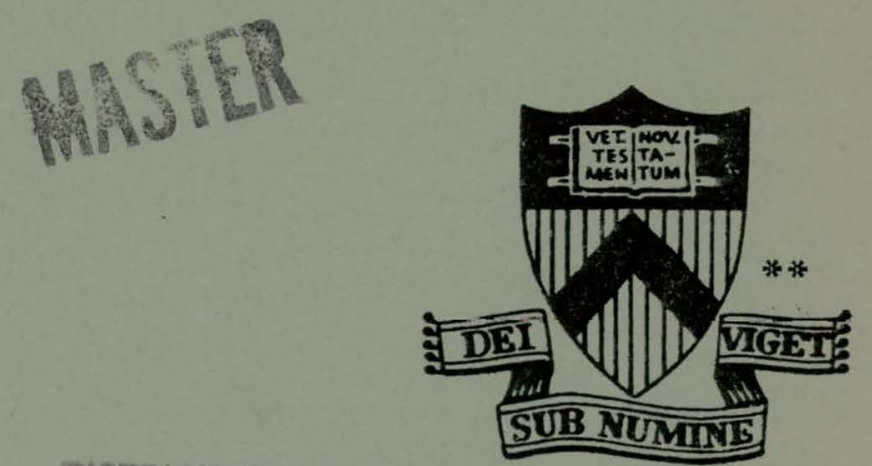

DISTRIBUTION OF THIS DOCUMENT IS UNLIMITED

\section{PRINCETON \\ UNIVERSITY PRINCETON, NEW JERSEY}

\footnotetext{
This work was supported by Department of Energy Contract EY-76-C-02-3073. Reproduction, translation, publication, use and disposal, in whole or in part, by or for the United States Government is permitted.
} 


\section{DISCLAIMER}

This report was prepared as an account of work sponsored by an agency of the United States Government. Neither the United States Government nor any agency Thereof, nor any of their employees, makes any warranty, express or implied, or assumes any legal liability or responsibility for the accuracy, completeness, or usefulness of any information, apparatus, product, or process disclosed, or represents that its use would not infringe privately owned rights. Reference herein to any specific commercial product, process, or service by trade name, trademark, manufacturer, or otherwise does not necessarily constitute or imply its endorsement, recommendation, or favoring by the United States Government or any agency thereof. The views and opinions of authors expressed herein do not necessarily state or reflect those of the United States Government or any agency thereof. 


\section{DISCLAIMER}

Portions of this document may be illegible in electronic image products. Images are produced from the best available original document. 
NOTICE

This report was prepared as an account of work sponsored by the United States Government. Neither the United States nor the United States Energy Research and Development Administration, nor any of their employees, nor any of their contractors, subcontractors, or their employees, makes any warranty, express or implied, or assumes any legal liability or responsibility for the accuracy, completeness or usefulness of any information, apparatus, prodict or process disclosed, or fepresents that its use would not infringe privacely owned rights.

Printed in the United States of America. Available from

National Technical Information Service

U. S. Department of Commerce 5285 Port Royal Road

Springfield, Virginia 22151

Price: Printed Copy $\$ \ldots$; Microfiche $\$ 3.00$

NTIS

*Pages

$$
1-50
$$

51- 150

151-325

$326-500$

$501-1000$
Selling Price

$\$ 4.00$

5.45

7.60

10.60

13.60 
A HIGH-FIELD, HIGH-DENSITY TORAMAK POWER REACTOR

D. R: COHN, D. L. COOK, R. D. HAY, D. KAPLAN, K. KREISCHER,

L. M. LIDSKY, W. STEPHANY, J. E. C. WILLIAMS

Massachusetts Institute of Technology, National Magnet Laboratory, and Plasma Fusion Center, Cambridge, Massachusetts 02139

D. L. JASSBY, M. OKABAYASHI

Princeton Plasma Physics Laboratory, Princeton, New Jersey 08540

PPPL- 1347

October 1977

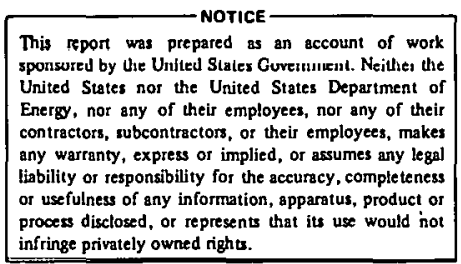

This paper was presented at the IAEA Workshop on Fusion Reactor Design, Madison, Wisconsin, October 10-12, 1977. 
A HIGH-FIELD, HIGH-DENSITY TOKAMAK POWER. REACTOR

D.R. COHN, D.L. COOK, R.D. HAY, D. KAPLAN, K. KREISCHER, L.M. LIDSKY, W. STEPHANY, J.E.C. WILLIAMS

Massachusetts Institute of Technology, National Magnet Laboratory, and Plasma Fusion Center, Cambridge, MA. 02139

D.L. JASSBY, M. OKABAYASHI

Princeton Plasma Physics Laboratory, Princeton, New Jersey, 08540

\section{ABSTRACT}

A conceptual design of a compact $\left(R_{0}=6.0 \mathrm{~m}\right)$ high power density (average $\mathrm{P}_{\mathrm{f}}=7.7 \mathrm{MW} / \mathrm{m}^{3}$ ) tokamak demonstration power reactor has been developed. High magnetic field $\left(B_{t}=7.4 \mathrm{~T}\right)$ and moderate elongation $(b / a=1.6)$ permit operation at the high density $\left(n(0) \approx 5 \times 10^{14} \mathrm{~cm}^{-3}\right)$ needed for ignition in a relatively small plasma, with a spatially-averaged toroidal beta of only $4 \%$ A unique design for the $\mathrm{Nb}_{3} \mathrm{Sn}$ toroidal-field magnet system reduces the stress in the high-field trunk region, and allows modularization for simpler disassembly. The modest value of toroidal beta permits a simple, modularized plasma-shaping coil system, located inside the TF coil trunk. Heating of the dense central plasma is attained by the use of ripple-assisted injertion of $120-\mathrm{keV} \mathrm{D}^{\circ}$ beams. The ripple-coil system also affords dynamic control of the plasma temperature during the burn period. A FLIBE-1ithium blanket is designed especially for highpower-density operation in a high-field environment, and gives an overall tritium breeding ratio of 1.05 in the slowly pumped lithium. 


\section{INTRODUCTION}

This report describes the conceptual design of a high-field compact tokamak reactor (HFCTR) which operates at high power density $\left(<\mathrm{P}_{\mathrm{f}}>=7.7 \mathrm{MW} / \mathrm{m}^{3}\right)$ to generate a fusion power 1 evel of $2440 \mathrm{MW}$ in a plasma with major radius of $6.0 \mathrm{~m}$. The relatively modest size leads to lower capital cost and to moderate unit output power level, while the high power density affords reduced cost $/ \mathrm{kW}$. The features of the HFCTR conceptual design are the following :

(1) H1gh Plasma Density $\left(\mathrm{n}(0) \approx 5 \times 10^{14} \mathrm{~cm}^{-3}\right)$ :

Based upon the "empirical scaling law". for energy confinement time [1], [2] $\left(\tau_{E} \sim n a^{2}\right)$, high density operation permits a reduction in the plasma size required for ignition. High $\mathrm{n}$ is also known to result in relatively small impurity content [3]. Finally, high fusion power density. is achieved because $\mathrm{P}_{\mathrm{f}} \sim \mathrm{n}^{2}$.

\section{(2) Diametrica11y Reacting, Modularized, Nb $3 \mathrm{Sn}_{\mathrm{TF}}$ Coils:}

In order to achieve high $n$ at modest values of toroidal beta $\left(\left\langle\beta_{t}\right\rangle=4 \%\right.$, a high magnetic field $\left(B_{t}=7.4 \mathrm{~T}\right)$ is required. The tensile stress in the trunk of the $\mathrm{Nb}_{3} \mathrm{Sn}$ magnet system at $13.1 \mathrm{~T}$ is shared with the core by the use of circular reaction rings to transmit the tensile loading between diametrically opposite D coils [4]. The feature of reaction rings also allows full modularization of the $\mathrm{Nb}_{3} \mathrm{Sn}$ magnet system for improved accessibility and maintenance.

\section{(3) Simple, Modularized Plasma Shaping-Coil System}

The plasma elongation requirements for achieving the $4 \%$ plasma beta $(b / a \approx 1.6)$ are relatively modest, allowing a simple plasma-shaping coil system. The superconducting hexapole field-shaping coil is located in the throat of the TF coils. The copper coils located inside the TF modules are 
segmented with electrical connections formed by pressure contacts.

\section{(4) Pulsed Nulling-Field Coils}

The principal vertical-field coils are operated continuously, while a separate copper nulling-coil system provides the necessary field change during start-up [4]. This nulling-coil system greatly minimizes the pulsed power and stored-energy requirement, as only the vertical field in the volume immediately surrounding Llie plasilla ls pulsed.

\section{(5) Ripple-Trapping Beam Injection}

Adequate heating of the dense HFCTR plasma is obtained by using a controlled toroidal-field ripple to enhance the penetration of energetic ions formed by near-vertical injection of $120-\mathrm{keV} \mathrm{D}^{\circ}$ beams [5].

\section{(6) FLIBE-Lithium Blanket}

The blanket coolant is FLIBE, which is characterized by high density and low electrical conductivity, thus minimizing the pumping power requirements at high neutron wall loadings in a high magnetic field environment in a small-size blanket. Slowly pumped, nearly stagnant lithium is used for tritium breeding, giving an overall breeding ratio of 1.05 . This blanket system obviates the need for high flow rates of high temperature lithium and is therefore less susceptible to major accidents due to high circulating pressure.

\section{PLASMA CHARACTERISTICS}

The "empirical scaling" relation for the energy confinement time was used as a guideline for determining the plasma halfwidth needed to insure ignition. The scaling relation is $\tau_{E}=3.2 \times 10^{-19} q^{\frac{1}{2}} \bar{n}_{\ell} \cdot \frac{2}{a}[1,2]$, where all quantities are in cgs units, $\bar{n}_{\ell}$ is the line average density and $\bar{a}$ is the average plasma radius. Reference [2] summarizes the experimental data on which this scaling relation is based. The plasma halfwidth was chosen to be as small as possible consistent with insuring a reasonable margin of safety for the attainment 
of ignition. The margin of safety for a given $Z_{\text {eff }}$ is defined as

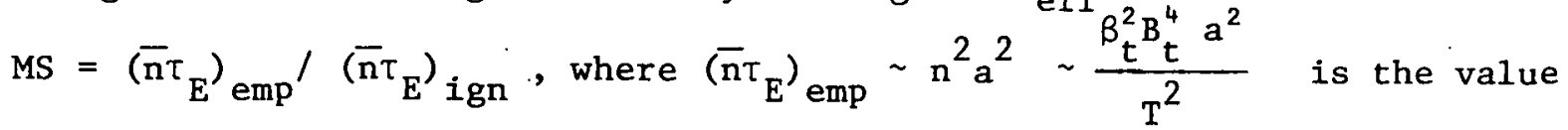
of $\left(\bar{n} \tau_{E}\right)_{\text {emp }}$ obtained from the empirical scaling law, and $\left(\vec{n} \tau_{E}\right)$ ign is the value of $\bar{n} \tau_{E}$ needed for ignition. The maximum permitted values of $\left(\bar{n} \tau_{E}\right)$ emp are limited by the requirement that $\left(\tau_{E}\right)$ emp be less than $\left(\tau_{E}\right)_{N C}$, where $\left(\tau_{E}\right)_{N C}$ is the energy confinement time obtained from neoclassical scaling. For $Z_{\text {eff }}=1.2, M S=4.5 ;$ while for $Z_{\text {eff }}=1.5, M S=2.2$. A further 1 ower limit on the plasma halfwidth is set by the aspect ratio becoming so large that the plasma beta is unacceptably sma11. Based upon these considerations, the plasma halfwidth was chosen to be $1.2 \mathrm{~m}$.

The reference operating parameters for the HFCTR are listed in Table I. Figure 1 shows the possible range of density, temperature and average wall loading for the HFCTR. The upper limit on density and temperature is determined by the plasma pressure limit. The lower limit is determined by the requirement for ignition with a margin of safety $=1$. Within this range the thermal power production can vary from about $660 \mathrm{MW}_{\text {th }}$ to $3670 \mathrm{MW}$ th The corresponding average wall loading varies from $0.85 \mathrm{MW} / \mathrm{m}^{2}$ to $4.7 \mathrm{MW} / \mathrm{m}^{2}$. In addition, it may be desirable that the collisionality of the plasma be greater than $\sim 0.1$. This value of collisionality $\left(v_{\text {ej. }} A / \omega_{\text {be }}\right)$ of the plasma be of the range characteristic of present devices, where the empirical scaling law is known to be valid. Contours for collisionality $=0.1$ and 0.05 are shown in Figure 1 .

\section{MAGNET DESIGN}

The design of a magnet system to attain the highest practical toroidal fields in a compact tokamak requires the integration of a number of conflicting 
factors. The aspect ratio and the ratio of toroidal field on axis to the field in the magnet windings are determined by the need to deal with large forces associated with high-field operation. and by the requirement of a satisfactory blanket thickness. In addition it is desirable to modularize the construction to facilitate dissassembly for maintenance. Further practical constraints are the need to minimize pulse power requirements, to limit steady state power dissipation in copper coils, and to reduce refrigeration losses in superconducting coils.

The coil configuration shown in Figure 2 has been developed to fulfill the objectives wi.thin the inherent constraints. Table II 1ists the principal characteristics of the magnet systems. Figure 3 shows the basic TF octant module.

A unique design for toroid force containment uses circular reaction rings at the top and bottom which mutually support the outward forces developed in the outer arc of opposed D coils. [4] As a result, the tensile forces on the center straight sections of the toroidal field coils can be reduced. The tensile load on the center straight section of the toroidal field coils originates in the vertical component of force on the inner arcs of these coils. This load can be arbitrarily reduced by decreasing the inner arc length, at the expense of increased load in the reaction rings and in the outer arcs of the structural support plates.

A locking ram transmits the toroidal coil force to the reaction ring. When this ram is released, the rings (and the external vertical field coils) can be axially displaced to permit removal of the toroidal sector assemblies. (The neutral beam injectors are previously disconnected and withdrawn.)

The plan view in Fig. 4 shows the features of the demountable sectored 
toroidal field coils. Two independent coils are mounted on a modular octant : of the blanket and shield system. A major maintenance operation would involve the replacement of one complete octant section. The cryostat walls surrounding the mating side of the vertical section of the $\mathrm{TF}$ core and the core are moveable, so that in the energized state a high-pressure solid contact is made. Conversely, when separated the cryostat vacuum walls will distend to limit thermal conduction and radiation, allowing the internal structure to remain cold. This design avoids the necessity of warming the entire magnet system Lu servlee une station. It is necessary to maintain a helium atmosphere around the TF core to eliminate gas condensation on cold surfaces.

The structural plates which carry the superconductor around the toroid, contain slots in which the insulated superconductor is inserted. An additional structural $\mathrm{C}$ encloses these plates to limit the tensile stress in the outer arc of the conductor rings to $210 \mathrm{MPa}$, a strain of $1 / 10 \%$ in stainless steel. Extensions from the $\mathrm{C}$ engage the reaction rings and are inset into the structural core to provide vertical tensile load sharing between the toroidal coil structure and the core. This arrangement allows the ohmic heating coil to be located at the largest possible diameter within the throat of the toroidal field coils while at the same time retaining essential modularity of the system. Again, only with the concept of reaction rings can this be achieved.

The vertical-field system is chosen to maximize the flexibility of coil location and to reduce the pulsed energy requirement. A novel feature consists of the placement of a nulling field coil inside the toroid, and driven to oppose the DC vertical field. [4] It is regulated to provide the correct vertical field start-up and its effective volume is limited to roughly the plasma volume. The nulling-coil field is decreased as the plasma current increases, 
simultaneously providing the correct equilibrium field and about half of the required $130 \mathrm{~Wb}$ of fast flux. The energy transfer of $500 \mathrm{MJ}$ in this system is only $1 / 4$ that of the total equilibrium field. Fig. 5 shows the timedependent magnetic flux transfer and the build-up of plasma current.

The main vertical field coils consist of a superconducting dipole outside the toroid and a DC copper quadrupole inside. The copper coils located within the toroid are segmented, retaining the modular concept with pressure contacts to form electrical series connections between segment ends. Present experience suggests that reliable pressure contacts can be made at current densities consistent with those to be used in the copper coils. At a current of 3.2 MA the DC copper quadrupole coils dissipate approximately $50 \mathrm{MW}$, of which the contacts will consume only $1 \mathrm{MW}$. The peak power in the pulsed nulling coils is $66 \mathrm{MW}$ and the average power over the $500 \mathrm{sec}$ burn is about $\frac{1}{2} \mathrm{MW}$.

The superconducting hexapole coil is located in the throat and is independent of the toroid modules. This coil provides the field gradient needed to make the D-shaped plasma.

The additional flux needed for startup and for maintaining the burn is supplied by a superconducting ohmic-heating coil in the throat. Supplementary compensating coils above and below the toroid modules are adjusted to make this field as small as possible at the plasma. To limit the maximum field and stored energy, the $\mathrm{OH}$ coils are driven from $4.1 \mathrm{~T}$ through zero to $-4.1 \mathrm{~T}$ for a total flux transfer of about $120 \mathrm{~Wb}$. The pulsed-coil conductor is made from a NbTi superconducting composite.

The average field increment imposed on the TF coil from the vertical field pulse and the induced plasma current is $<1 \mathrm{~T}$. The electromagnetic losses in the twisted superconductor from this imposed field are estimated to 
be $\tilde{<3} \mathrm{~kW}$. This loss necessitates a refrigeration input power of the order of 1MW averaged over the burn duration. The imposition of an external field pulse on a superconductor greatly complicates the conductor design, especially at high fields. However, the critical temperature of $\mathrm{Nb}_{3} \mathrm{Sn}$ is near $7 \mathrm{~K}$ at $13 \mathrm{~T}$, which allows some margin for thermal diffusion of the energy dissipated during the field pulse. Further refinement of the vertical-field coil design is expected to result in a decrease in the pulsed losses.

\section{PLASMA HEATING AND TEMPERATURE CONTROL}

Conventional neutral-beam injection requires beam energies of about $400 \mathrm{keV} \mathrm{D}^{\circ}$ in order to insure penetration of the fast neutrals into the central plasma region at the highest densities of interest $\left(\sim 5 \times 10^{14} \mathrm{~cm}^{-3}\right)$. Efficient neutral beams of this energy could become feasible on an acceptable time-scale if high-current negative-ion beams are developed during the next ten years. However, the reference heating scheme in the present design makes use of the ripple-trapping injection method, ${ }^{[5]}$ for which state-of-the-art $120-\mathrm{keV} \mathrm{D}^{\mathrm{O}}$ beams are adequate. (Expanding-plasma start-up schemes, with conventional injection, would also make use of beam energies in the range 80 to $120 \mathrm{keV}$.$) Eight beam injectors, each delivering 12.5 \mathrm{MW}$ at $120 \mathrm{keV}$, are installed for near-vertical injection, as indicated in Figure 2. The required access area constitutes about $1 \%$ of the torus wall area. A toroidal-field ripple with significant top-bottom asymmetry is produced by special rippleinducing coils located in the horizontal plane $3.5 \mathrm{~m}$ below the magnetic axis, inside each of the eight TF modules. The eight sets of ripple coils produce alternate maxima and minima in the toroidal field, with the injectors located at the $8 \mathrm{minima}$. Energetic ions formed from the neutral beams are trapped in 
the ripple magnetic well, and drift upward to the central plasma region where the ripple becomes small $(<1 \%)$ and the ions are detrapped. The coils are activated only during the $4 \mathrm{sec}$ higher-density period of the start-up stage. Each single-turn ripple coil carries $1.8 \mathrm{MA}$, and the pulsed Joule heating in the complete coil set is $130 \mathrm{MW}$. The power consumed is $1 \mathrm{MW}$ when averaged over the burn time of $500 \mathrm{sec}$.

Fusion alpha particles begin to contribute significantly to plasma heating when $T_{i}$ reaches about $5 \mathrm{keV}$. The vertically asymmetric ripple causes a fast radial drift of the banana-trapped alphas (about one-third of the total alpha population), so that only about $70 \%$ of the alpha energy is deposited in the plasma. [5] Once ignition is attained, the ripple coils are deactivated. If the empirical confinement scaling remains valid at the operating temperature, then the equilibrium operating point is unstable to temperature perturbations. It then becomes profitable to activate one or more pairs of ripple coils during the burn, to vary the fraction of confined alpha particles in response to temperature perturbations. [6] Control is sufficiently rapid so that temperature excursions can be limited to at most $5 \%$. The time-averaged ripple-coil dissipation is estimated to be 5 to $10 \mathrm{MW}$ for this control.

Even without active thermal stabilization, an upper limit to a temperature runaway would probably be set by the onset of MHD ballooning modes [7] when the plasma beta exceeds $5 \%$. These modes are expected to result in enhanced radial heat diffusion, and thus effectively introduce an unfavorable temperature dependence of confinement time.

In the event that ${ }^{n} \tau_{E}$ turns out to be several times the value needed for equilibrium ignition, a fixed amount of radiating high-Z gas (e.g. xenon) can be added to provide an equilibrium operating point. Less than $0.1 \%$ of xenon is required. 


\section{BLANKET AND SHIELD}

The basic concept behind the blanket design is to use lithium as the breeding material while cooling the blanket with the molten salt, FLIBE (2 $\left.\mathrm{LiF} \cdot \mathrm{BeF}_{2}\right)$. This blanket is designed specifically for use at high neutron wal1-loadings in intense magnetic fields in a compact device. The requirement of small blanket thickness demands that a fairly dense coolant be used. The liquid metals would require unacceptable pumping power levels because of MHD effects in the high magnetic field, and pressurized gases - even at 50 atm are not compatible with minimum blanket thickness. FLIBE is attractive because it is characterized by high density and good heat-transfer properties, while having a relatively low electrical conductivity. [8] It is chemically stable, relatively noncorrosive, and neutronically favorable. In this arrangement FLIBE is used only for cooling the first wall and blanket it is not used for tritium breeding. The pumping power requirement for the blanket in the reference design of the HFCTR is of the order of $10 \mathrm{MW}$ during operation.

The molybdenum alloy TZM (99.39\% Mo, $0.5 \% \mathrm{Ti}, 0.08 \% \mathrm{Zr}, 0.03 \% \mathrm{C}$ ) is an appropriate structural material choice. It can be utilized at the relatively high temperatures required for molten salt operation and is chemically compatible with FLIBE. The problem of fabrication associated with TZM has, to some extent, been alleviated by a modular blanket design which allows sections of the blanket to be completely fabricated at the point of manufacture, where good quality control is feasible. The design also allows for the primary vacuum welds to be made with stainless steel in the moderator/reflector region.

A diagram of the "outboard" blanket and shield is shown in Fig. 6. The 
first surface seen by the plasma consists of a set of tubes which are convectively cooled by FLIBE passing through them. These tubes intercept all the alpha power $\left(\sim 1 \mathrm{MW} / \mathrm{M}^{2}\right.$ as a surface heat 1oad). Further into the blanket are a number of molten lithium breeding regions ( $95 \% \mathrm{Li}-5 \% \mathrm{Mo})$ which are cooled by channels filled with FLIBE. The size of the lithium regions is limited by the constraint that the peak lithium (and therefore structure) temperature not exceed $1000^{\circ} \mathrm{C}$. The lithium is essentially stagnant, and flows only fast enough to maintain a low tritium inventory (cycle time $\sim 1$ day). Beyond the breeding regions is the two-part graphite and stainlesssteel moderator/reflector and the composite stainless-steel and boron carbide shield. Additional shielding on the outboard side is placed just inside the TF-coil cryostat wall.

The "inboard" blanket/shield thickness is approximately 1.0 meter, while the "outboard" blanket/shield thickness is as large as 1.3 meters.

The inboard blanket/shield serves mainly as a shield with minimal breeding. Neutronics analysis with the I-D ANISN code shows that the tritium breeding ratio of the outboard blanket/shield is 1.23 . The net tritium breeding ratio for the entire blanket is about 1.05 .

\section{ACKNOWLEDGMENT}

This work was supported by the U.S. Energy Research and Development Administration, Div. of Magnetic Fusion Energy. 


\section{REFERENCES}

[1] COHN, D.R., PARKER, R.R., and JASSBY, D.L., Nucl. Fusion 16 (1976) 31.

[2] JASSBY, D.L., COHN, D.R., and PARKER; R.R., Nucl. Fusion 16 (1976) 1045.

[3] PARKER, R.R., Trans. Am. Nuc1. Soc., 26 (1977) 17; PLT group, 8th Eur. Conf. on Controlled Fusion and Plasma Physics (Prague 1977), to be published.

[4] WILLIAMS, J.E.C., COHN, D.R., JASSBY, D.L. and PARKER, R.R., Trans. Am. Nucl. Soc. 24 (1976) 44; COHN, D.R. JASSBY, D.L. P.ARKER, R.R. and WILLIAMS, J.E.C., The Technology of Controlled Nuclear Fusion, (Proc.2nd Top. Mtg., Richland, WA, 1976) III, 931.

[5]. JASSBY, D.L. and GOLDSTON, R.J., Nuc1. Fúsion 16 (1976) 613.

[6] JASSBY, D.L. and TOWNER, H.H., Trans. Am. Nucl. Soc. 24 (1976) 56.

[7] TODD, A.M. et.a1.,Phys. Rev. Lett. $\underline{38}$ (1977) 826.

[8] GRIMES, W.R. and CANTÜR, S., The lhemistry of f'usion Technology (Plenum Press, N.Y., 1973) 161. 
TABLE I

REFERENCE HFCTR PARAMETERS

Machine Parameters
Major radius, $R_{o}(m)$
6.0
Plasma halfwidth, a(m)
1.2
Aspect ratio
5.0
Plasma elongation (D shape)
1.6
Field at plasma, $B_{t}(T)$
7.4
Maximum field at winding, $B_{m}(T)$
13.1
Plasma volume, $v_{p}\left(m^{3}\right)$
317
First wa11 area, $A_{W}\left(m^{2}\right)$
475

\section{Plasma Parameters}

$\begin{array}{ll}\text { Safety factor at } r=a, q(a) & 3.0 \\ \text { Average toroidal beta, }\left\langle\beta_{t}>\right. & 0.04 \\ \text { Plasma current, (MA) } & 6.7 \\ \text { Electron density, } n\left(m^{-3}\right) & 5.2 \times 10^{20}\left(1-\frac{r^{3}}{a^{3}}\right) \\ \text { Electron ion temp, } T(\mathrm{keV}) & 12.4\left(1-\frac{r^{2}}{a^{2}}\right) \\ Z_{\text {eff }}(\text { Helium }+M o) & 1.2 \\ \left(\bar{n} \tau_{E}\right) \text { emp } /\left(\bar{n} \tau_{E}\right) \text { ign } & 4.4 \\ \text { Beam Power, } P_{b}(M W) & 100 \\ \text { Beam Energy, } W_{b}(\mathrm{keV}) & 120\end{array}$

Power Production

Av. Fusion power densily, $\overline{\mathrm{P}}_{\mathrm{f}}\left(\mathrm{MW} / \mathrm{m}^{3}\right)$

7.7

14-Mev neutron wal1 loading, $\mathrm{P}_{\mathrm{W}}\left(85 \%\right.$ duty, $\left.\mathrm{MW} / \mathrm{m}^{2}\right)$

3.4

Total fusion power, $\overline{\mathrm{P}}_{\mathrm{f}} \mathrm{V}_{\mathrm{P}}$

Av. thermal power, $\mathrm{P}_{\text {th }}(85 \%$ duty, MW)

Sross electric power, $P_{\mathcal{G}} \quad(35 \%$ efficiency, MW $) \quad 870$

Net electric power, $\mathbf{P}_{\mathbf{n}}$

(MW)

77.5

Plant efficiency, $\eta_{p}(\%)$ 
TABLE II

HFCTR MAGNET SYSTEM PARAMETERS

TF Coils

Number of coils

16

Current in each coil

13.9 MA

Field at $R_{0}=6 \mathrm{~m}$

$7.4 \mathrm{~T}$

Maximum field in coil at $\mathrm{R}=3.4 \mathrm{~m}$

$13.1 \mathrm{~T}$

Inside aperture.

$6.5 \mathrm{~m} \times 10.5 \mathrm{~m}$

Ripple at outside plasma surface

$1 . \% \max$.

Maximum stress in winding structure

$210 \mathrm{MPa}$ (0.1\% strain)

Stored energy

$40 \mathrm{GJ}$

Weight of each coil assembly

425 tonnes

\section{$\underline{\text { VF Coils }}$}

Superconducting dipole coils

-21.2 MA

Copper quadrupole coils

$6.4 \mathrm{MA}$

Copper null-field coils

6.4 MA pulsed

Copper null-field stored energy

$500 \mathrm{MJ}$

Superconducting hexapole coils

$-8.0 \mathrm{MA}$

VF Stored energy

2 G GJ

$\mathrm{OH}$ Coils

38 MA total

OH Field

$4.1 \mathrm{~T}$ max.

$\mathrm{OH}$ Stored energy (fast and slow pulsed)

$\pm 1 \mathrm{GJ}$

\section{Magnet System}

Peak power input ( $5 \mathrm{sec}$ start-up)

565 MW

Average power input ( $500 \mathrm{sec}$ burn)

80 MW

Startup flux requirement

$135 \mathrm{~Wb}$

Burn flux requirement

$60 \mathrm{~Wb}$ 


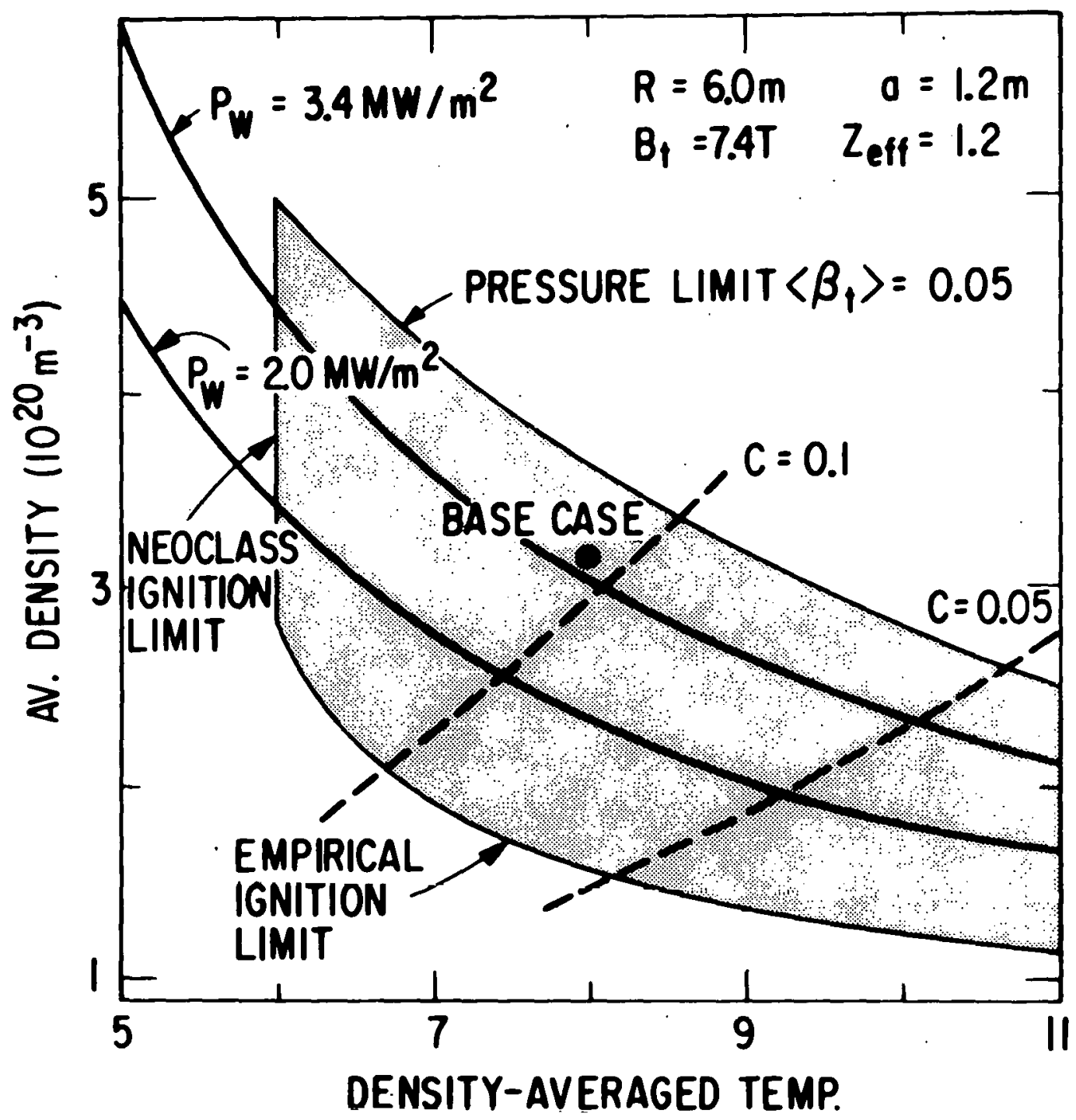

Fig. 1. Shaded area is the permissible range of reactor operation for the parameters shown. Ignition limits for both empirical and neoclassical scaling laws are indicated. $\mathrm{C}=$ plasma collisionality. 


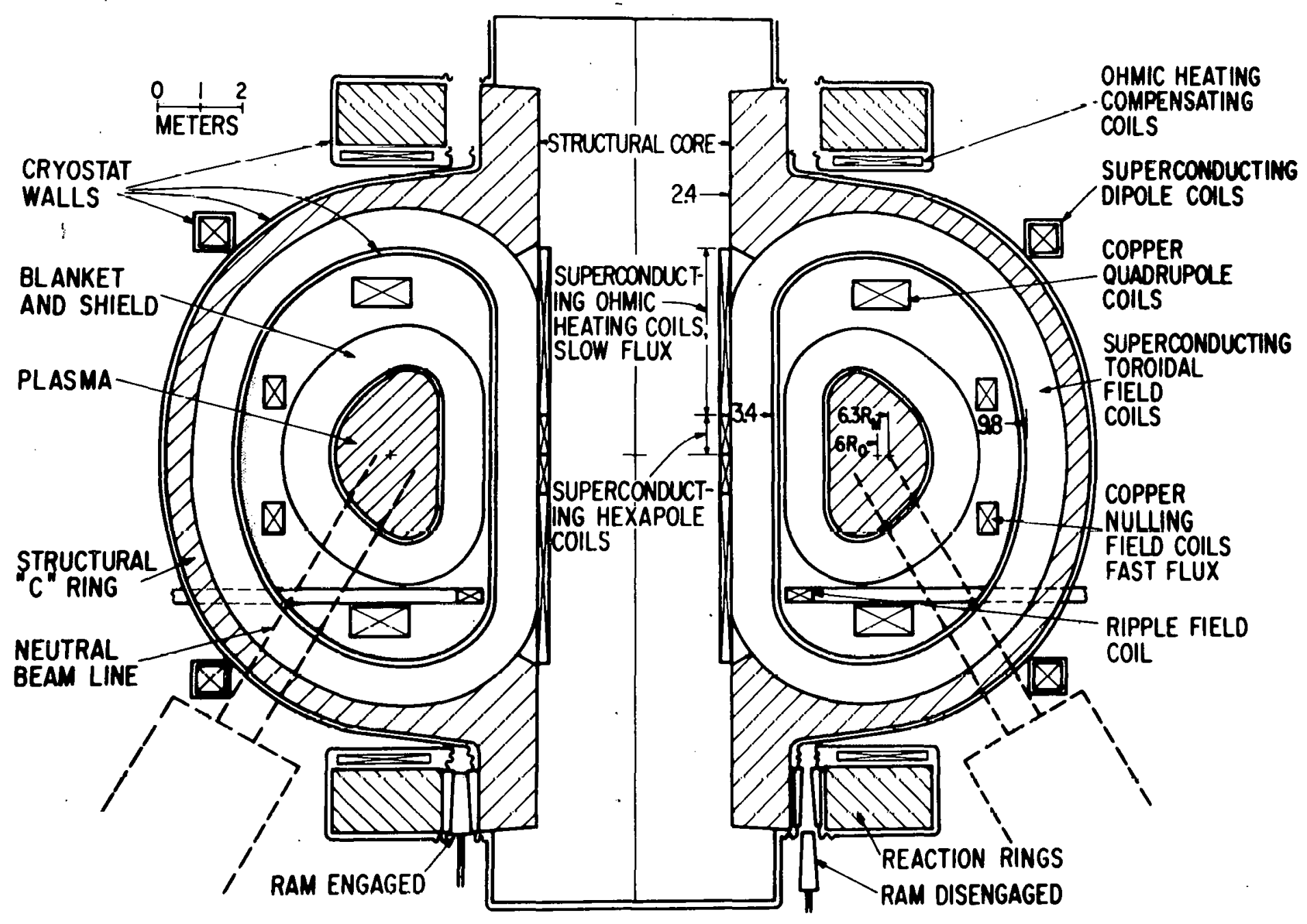

Fig. 2. Elevation view of HFCTR, showing all magnet systems. 


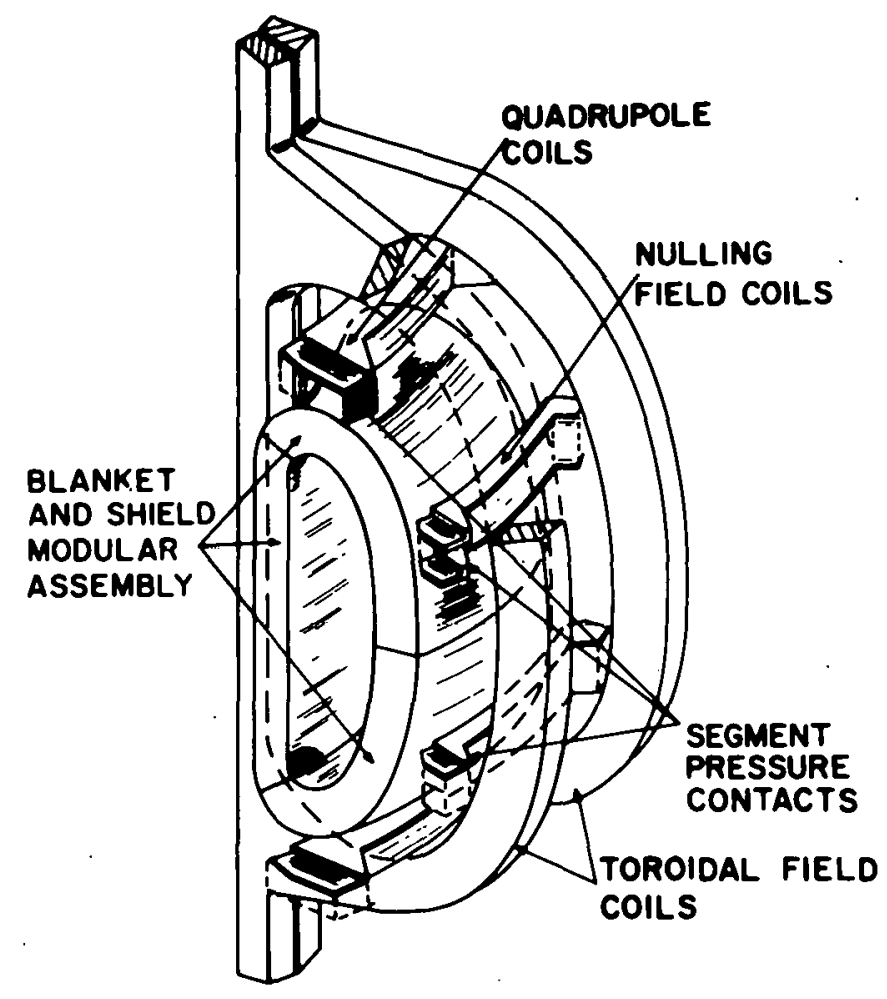

Fig. 3. Assembly of one octant module. 


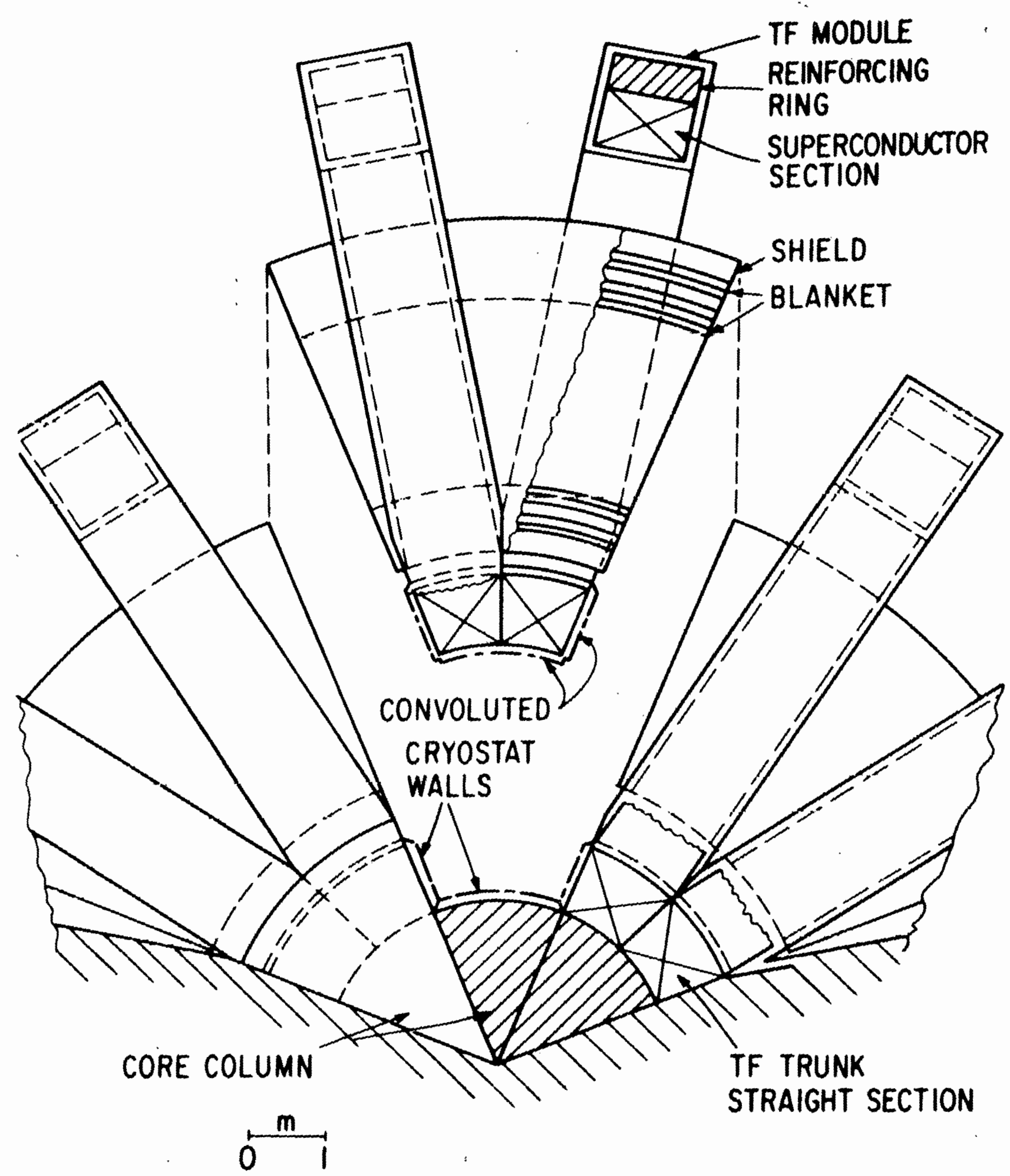

Fig. 4. Top view of toroidal-field magnet system. 


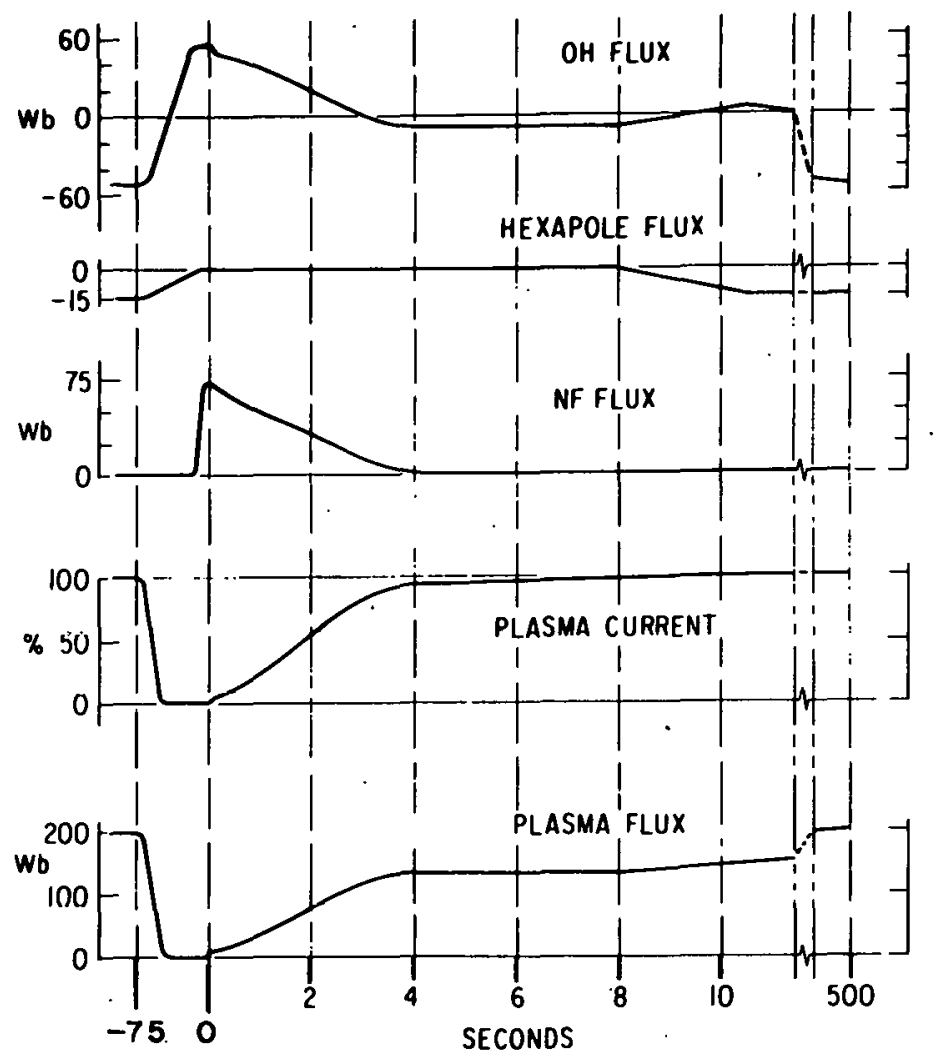

Fig. 5. Waveforms of magnetic flux and plasma current.

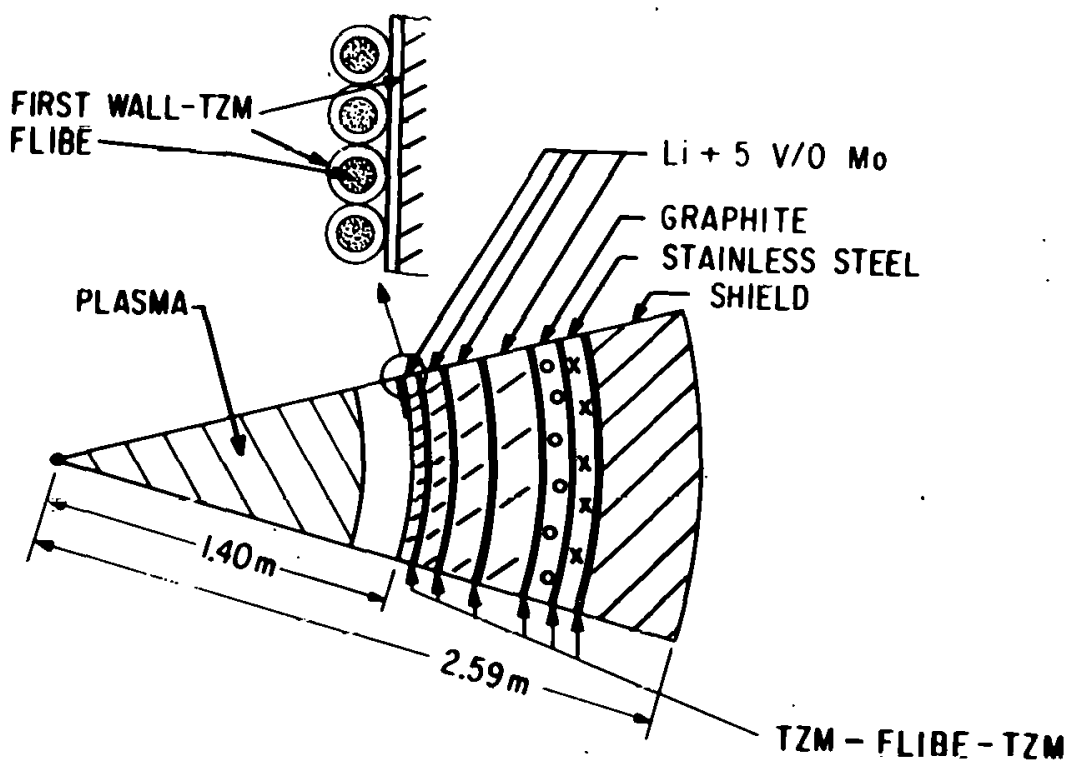

Fig. 6. Section diagram of outboard blanket and shield. 